\title{
Circulating vitamin D level and mortality in prostate cancer patients: a dose-response meta-analysis
}

\author{
Zhen-yu Song', Qiuming Yao' ${ }^{2}$, Zhiyuan Zhuo ${ }^{1}$, Zhe Ma' ${ }^{1}$ and Gang Chen ${ }^{1}$ \\ 'Department of Urology, Jinshan Hospital of Fudan University, Shanghai, China \\ ${ }^{2}$ Department of Endocrinology, Jinshan Hospital of Fudan University, Shanghai, China \\ Correspondence should be addressed to G Chen: chgan305@163.com
}

\begin{abstract}
Previous studies investigating the association of circulating 25-hydroxyvitamin D level with prognosis of prostate cancer yielded controversial results. We conducted a dose-response meta-analysis to elucidate the relationship. PubMed and EMBASE were searched for eligible studies up to July 15, 2018. We performed a dose-response metaanalysis using random-effect model to calculate the summary hazard ratio (HR) and $95 \% \mathrm{Cl}$ of mortality in patients with prostate cancer. Seven eligible cohort studies with 7808 participants were included. The results indicated that higher vitamin D level could reduce the risk of death among prostate cancer patients. The summary HR of prostate cancer-specific mortality correlated with an increment of every $20 \mathrm{nmol} / \mathrm{L}$ in circulating vitamin D level was 0.91 , with $95 \% \mathrm{Cl} 0.87-0.97, P=0.002$. The HR for all-cause mortality with the increase of $20 \mathrm{nmol} / \mathrm{L}$ vitamin D was $0.91(95 \% \mathrm{Cl}: 0.84-0.98, P=0.01)$. Sensitivity analysis suggested the pooled HRs were stable and not obviously changed by any single study. No evidence of publications bias was observed. This meta-analysis suggested that higher 25-hydroxyvitamin $\mathrm{D}$ level was associated with a reduction of mortality in prostate cancer patients and vitamin $D$ is an important protective factor in the progression and prognosis of prostate cancer.
\end{abstract}

\author{
Key Words \\ - vitamin D \\ - mortality \\ - prostate cancer \\ - meta-analysis
}

\section{Introduction}

Prostate cancer (PCa) is one of the most common malignant tumors in male. In 2017, American Cancer Society reported 161,360 cases of newly diagnosed PCa, accounting for $20 \%$ of male tumors. Furthermore, its incidence and mortality ranked the first place and third respectively (1). The mortality of $\mathrm{PCa}$ was proposed to be associated with obesity, physical activity, smoking, antioxidants, etc. (2). At present, the treatment of PCa have caused serious economic burden (3). More useful treatment measures are urgently needed by people to improve the survival rate of prostate cancer patients.

The major circulating form of vitamin $\mathrm{D}$ in human body is 25-hydroxyvitamin $\mathrm{D}(25(\mathrm{OH}) \mathrm{D})$, which comes from vitamin $\mathrm{D}$ via 25-hydroxylation process in the liver. $25(\mathrm{OH}) \mathrm{D}$ can be converted into $1,25(\mathrm{OH})_{2} \mathrm{D}$ by $1 \alpha$-hydroxylase, which is the most active hormonal metabolite of vitamin D. As a hormone, $1,25(\mathrm{OH})_{2} \mathrm{D}$ binds to vitamin $\mathrm{D}$ receptor located in nucleus and functions. It is reported to play an important role in cellular proliferation (4), differentiation, apoptosis (5), angiogenesis (6) and metastasis (7). All these processes may regulate the development and progression of cancer.

A number of researches have been done to clarify the association between vitamin D and PCa. Some experimental studies indicated that vitamin D might play a crucial role in the occurrence and progression of 
PCa. One study demonstrated mutations of vitamin D receptor gene were associated with Gleason score (8). Furthermore, study showed that genetic variants in the vitamin D pathway had effects on the risk of progression, prostate cancer-specific mortality and recurrence of PCa (9). Recent studies have reported controversial results about the association of vitamin $\mathrm{D}$ with the survival rate of prostate cancer. For example, in newly diagnosed stage IV prostate cancer patients, no significant association of 25-hydroxyvitamin D with the prognosis of them was found (10). In contrast, other studies reported that higher 25-hydroxyvitamin D was related to improved prostate cancer prognosis $(11,12)$.

Therefore, the relationship between 25-hydroxyvitamin D level and mortality of PCa is still unclear. Hence, we conducted this analysis to explore whether circulating 25-hydroxyvitamin D level was correlated with the survival of PCa through a doseresponse meta-analysis.

\section{Materials and methods}

\section{Search strategy}

We searched PubMed and EMBASE databases from inception to July 15, 2018, for eligible studies on the relationship between vitamin $\mathrm{D}$ and mortality in prostate cancer patients. The terms used to retrieve literatures were the following: (vitamin D OR 25-hydroxyvitamin D OR $25(\mathrm{OH}) \mathrm{D})$ and (prostate cancer OR prostate carcinoma). We also referred to the reference lists from reviews or relevant papers to get more eligible researches. There was no language restriction.

\section{Selection criteria}

Reports were included in this dose-response meta-analysis if they met the criteria as follows: (1) the association between vitamin $\mathrm{D}$ and mortality in prostate cancer patients was reported; (2) the study type was cohort; (3) the risk estimates of mortality in prostate cancer patients, like HR and 95\% CI were reported. If the same data were used in several studies, we selected the publication with the largest number of cases or more details.

\section{Data extraction}

Data were extracted from eligible studies by two researchers independently. The information collected from each study contained of the first author's last name, publication year, country, follow-up time, number of cases and person-year, risk estimates with corresponding 95\% CIs and confounding factors adjusted in multivariable analysis. We extracted the risk estimates from the most completed adjusted model to decrease the risk of possible confounding. Disagreements were resolved by consensus among authors.

\section{Quality assessment}

We evaluated the quality of studies by use of the Newcastle Ottawa Scale (NOS) (13). According to its criteria, studies were assessed on the basis of three perspectives: selection, comparability and outcomes. If studies got seven or more stars, they were regarded as high quality. Differences were resolved by discussion.

\section{Statistical analysis}

We performed data analyses separately for two outcomes, namely all-cause mortality and prostate cancer-specific mortality. Pooled HRs were calculated to assess the impact of vitamin D level on the prognosis of patients. The method proposed by Greenland and Longnecker (14) and Orsini et al. (15) was used to estimate the HR per $20 \mathrm{nmol} / \mathrm{L}$

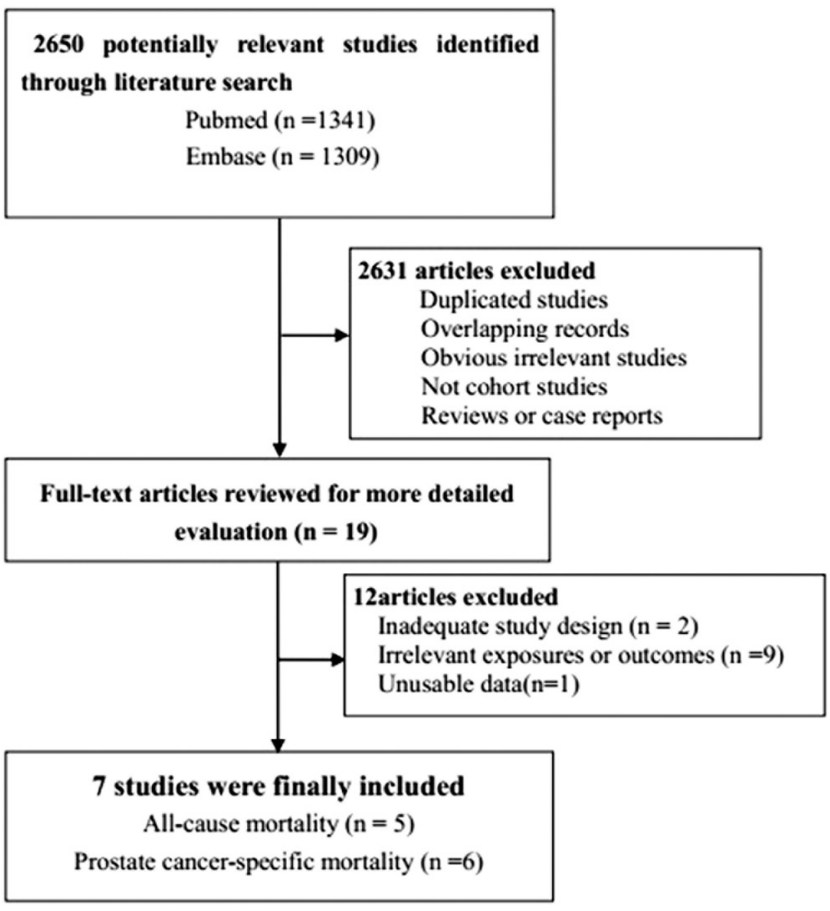

Figure 1

Flowchart of study selection in the meta-analysis. https://ec.bioscientifica.com

https://doi.org/10.1530/EC-18-0283 (c) 2018 The authors Published by Bioscientifica Ltd
This work is licensed under a Creative Commons Attribution-NonCommercial 4.0 International License. 


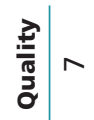

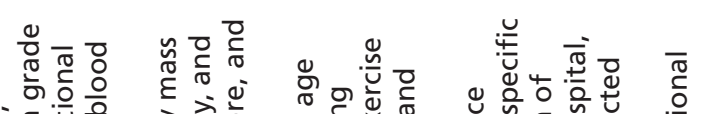

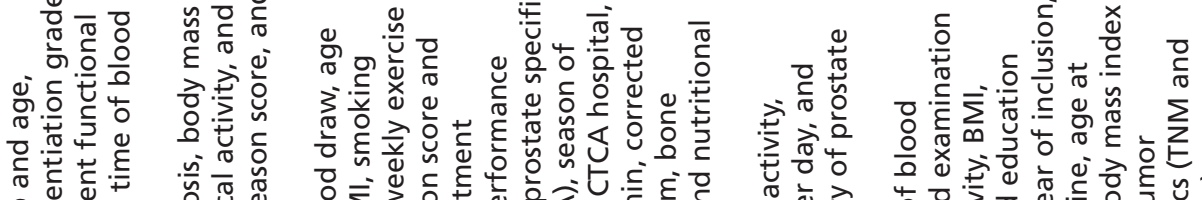

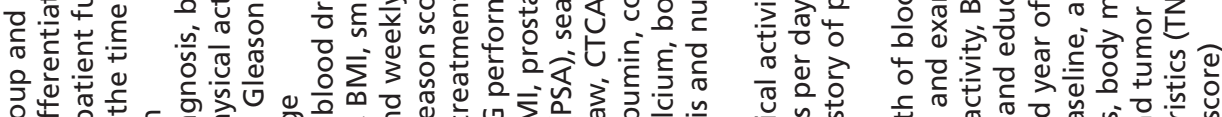

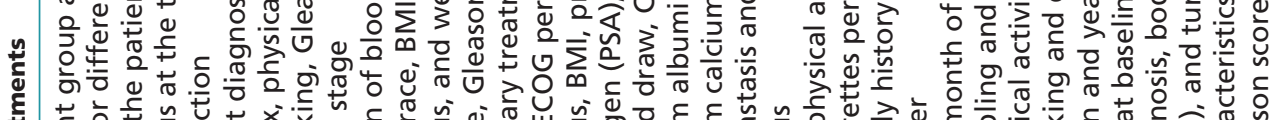

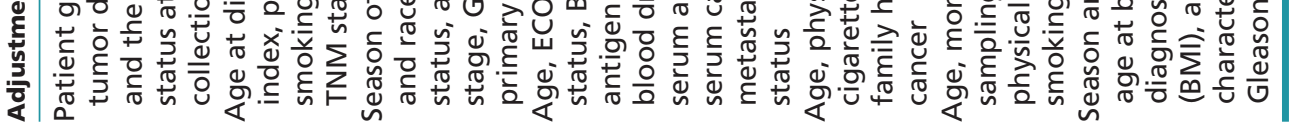



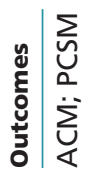

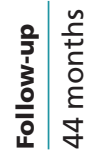

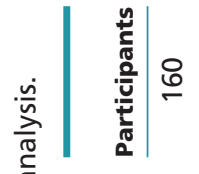

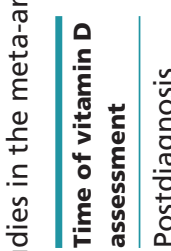

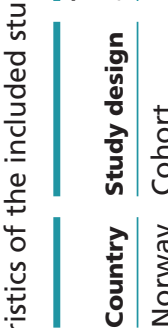

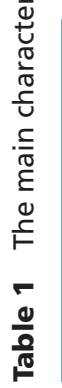

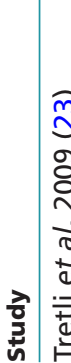

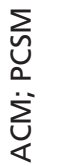

$\stackrel{\substack{\infty \\ \infty}}{\infty}$

8

$\sum_{\substack{0 \\ 0}}$

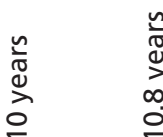

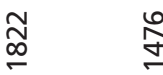

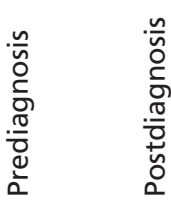

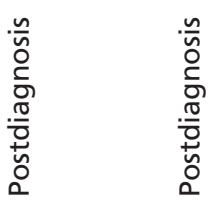

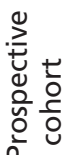

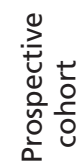

๕ั

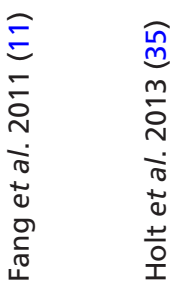

8

$\sum_{\substack{0 \\ 0}}$

$\stackrel{n}{\stackrel{n}{*}}$

$\stackrel{\sim}{\simeq}$

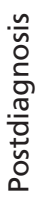

$\overleftarrow{\longleftarrow}$

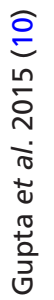

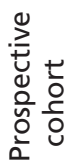

https://ec.bioscientifica.com

https://doi.org/10.1530/EC-18-0283

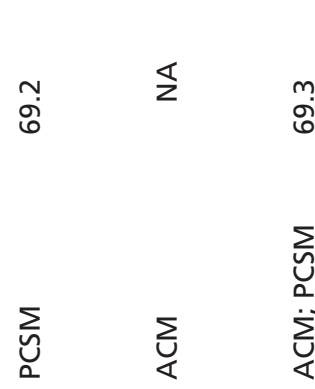

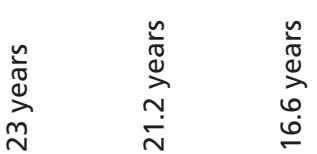

$\stackrel{\infty}{\stackrel{\infty}{N}} \quad$ \%

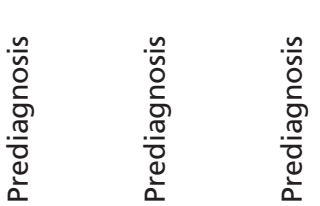

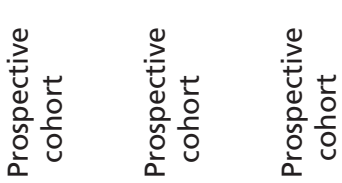

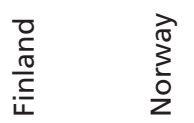

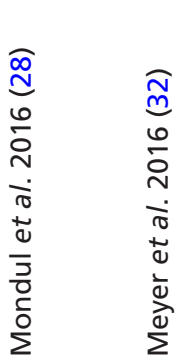

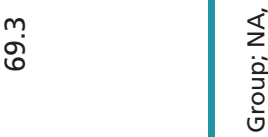
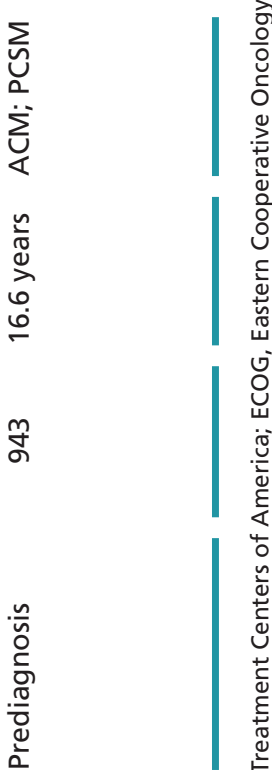

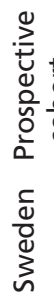

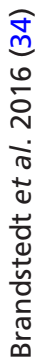


increase of vitamin D level. Statistical heterogeneity among studies was evaluated with the use of $\mathrm{Q}$ and $I^{2}$ statistic $(16,17)$. For the $\mathrm{Q}$ statistic, we regarded $P$ value $<0.10$ as statistically significant heterogeneity among studies. As to the $I^{2}$ statistic, $I^{2}$ more than $50 \%$ also suggested obvious heterogeneity. We utilized the random-effects model to combine HRs from single studies if obvious heterogeneity was observed (18). In the sensitivity analysis, studies were omitted one by one and the others were analyzed to evaluate the effect of single study on the summary risk estimates. Publication bias was assessed with the use of funnel plot and the Egger's test (19). We utilized Stata (Version 12.0) to perform this dose-response analysis. $P$ value $<0.05$ was reckoned as statistically significant difference.

\section{Results}

\section{Study selection and characteristics}

The selection process was showed in Fig. 1. We retrieved 2650 articles from PubMed and EMBASE databases (Fig. 1). A majority of them were excluded from our analysis because they did not belong to cohort studies or because outcomes were not associated with our analysis, leaving 19 articles for detailed evaluation by reading full-texts $(10,20,21$, $22,23,24,25,26,27,28,29,30,31,32,33,34,35,36,37)$. Twelve studies were then removed after reading their fulltexts. Two studies were excluded because of inadequate study design $(22,24)$. Nine studies were excluded because they did not contain prognosis data among prostate cancer patients $(20,21,26,27,29,32,35,37)$. One study was not qualified as a result of unusable data (36). Finally, a total of seven studies were included into our meta-analysis. The seven studies were published between 2009 and 2016 and the total number of prostate cancer participants was 7808. All of them were performed in developed countries, written in English (Table 1). Among them, three studies were conducted in USA $(10,30,34)$, two in Norway (23, 31), one in Finland (28), one in Sweden (33). All studies were prospective cohort type, except one from Tretli S. It is also a cohort study but hard to define it belongs to prospective or retrospective type. Meanwhile, the vitamin $\mathrm{D}$ assessments were performed after diagnosis in three studies, while the others were before diagnosis of prostate cancer. All studies reported adjusted HRs. Every research was adjusted for many confounding factors, such as age, BMI, drinking history and so forth. Participants were followed up from 4 to 21 years. Five studies contained HRs of all-cause mortality among prostate cancer patients, and six reported HRs of prostate cancer-specific mortality.

$\begin{array}{lr}\text { https://ec.bioscientifica.com } & \text { ○ } 2018 \text { The authors } \\ \text { https://doi.org/10.1530/EC-18-0283 } & \text { Published by Bioscientifica Ltd }\end{array}$

The quality assessment of those studies according to NOS criteria was also presented in the Table 1.

\section{5-hydroxyvitamin D and all-cause mortality}

We observed significant heterogeneity among five studies on all-cause mortality $\left(I^{2}=68.9 \%\right)$. Figure $2 \mathrm{~A}$ displayed the results of the dose-response analyses on all-cause mortality (Fig. 2A). A nonlinear relationship existed between 25-hydroxyvitamin $\mathrm{D}$ and risk of allcause mortality in prostate cancer patients, suggesting higher 25-hydroxyvitamin D level was associated with decreased risk of death from all causes among prostate cancer patients $(P=0.038)$. The summary $\mathrm{HR}$ of allcause mortality correlated with an increment of every $20 \mathrm{nmol} / \mathrm{L}$ in circulating vitamin D level was 0.91 (95\% CI:
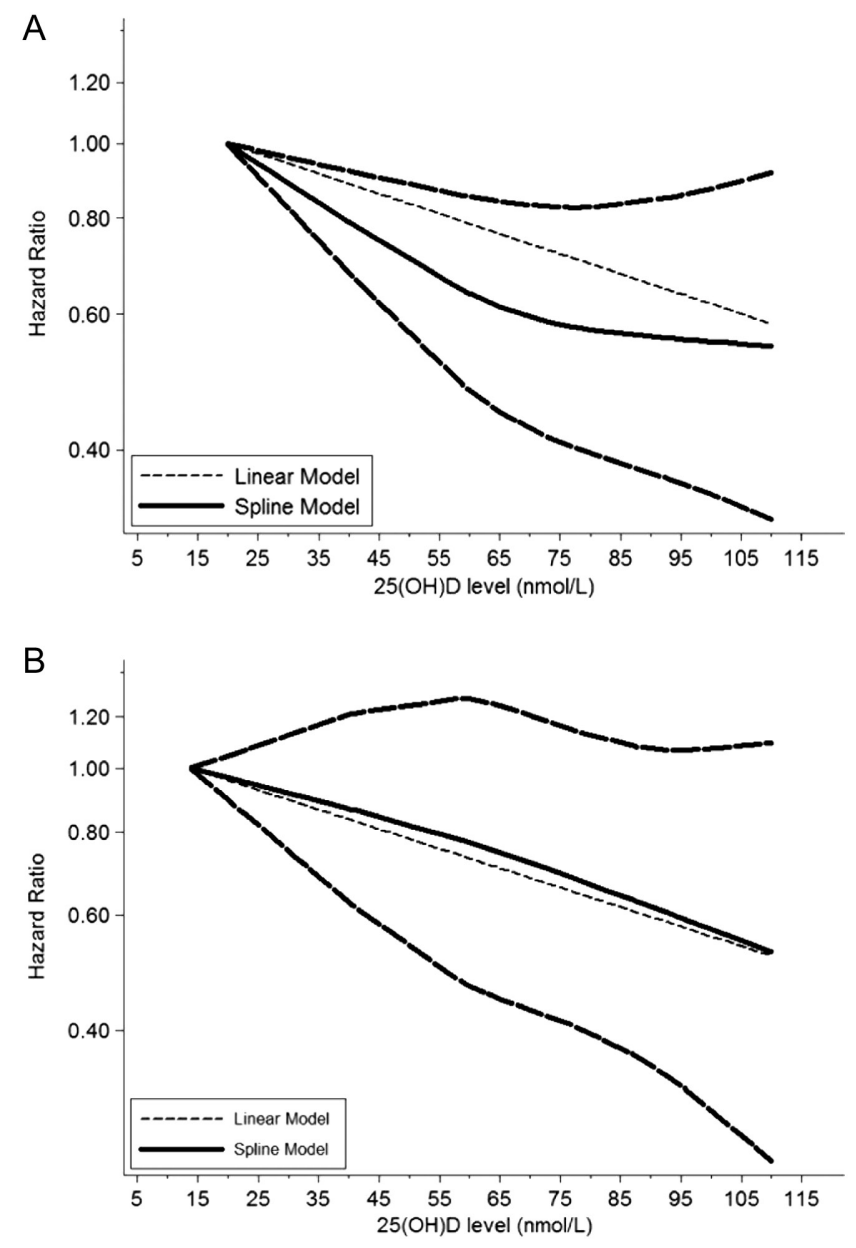

Figure 2

Dose-response relationships between 25(OH)D and risk estimates of all-cause mortality and prostate cancer-specific mortality. (A) Risk estimates with $95 \% \mathrm{Cl}$ for the association between $25(\mathrm{OH}) \mathrm{D}$ and all-cause mortality. (B) Risk estimates with $95 \% \mathrm{Cl}$ for the association between 25(OH)D and prostate cancer-specific mortality. 
0.84-0.98, $P=0.01$ ) (Fig. 3A). Sensitivity analysis suggested the pooled HRs were stable and not obviously changed by any individual study (Fig. 4A).

\section{5-hydroxyvitamin D and prostate cancer-specific mortality}

There was obvious heterogeneity observed among those six studies on prostate cancer-specific mortality $\left(I^{2}=53.4 \%\right)$. A nonlinear relationship between 25 -hydroxyvitamin $\mathrm{D}$ and risk of prostate cancer-specific mortality was also presented in Fig. 2B, indicating higher vitamin D level could decrease the mortality from prostate cancer (Fig. 2B). The summary HR of prostate cancer-specific mortality correlated with an increment of every $20 \mathrm{nmol} / \mathrm{L}$ in circulating vitamin D level were 0.91 (95\% CI: 0.87-0.97, $P=0.002$ ) (Fig. 3B). The sensitivity analysis showed the summary HRs were not markedly changed by any individual study (Fig. 4B), indicating no significant influence of single study on the results.

\section{Publication bias}

No risk of publication bias was observed in the funnel plots (Fig. 5). The outcomes from Egger's test also suggested that there were no publication bias for the analysis of allcause mortality $(P=0.143)$ and prostate cancer-specific mortality $(P=0.301)$.

\section{Subgroup analysis and meta-regression}

We conducted the subgroup analysis and meta-regression to detect the source of heterogeneity, which was presented in Table 2. Stratifying by the time of vitamin D assessment,

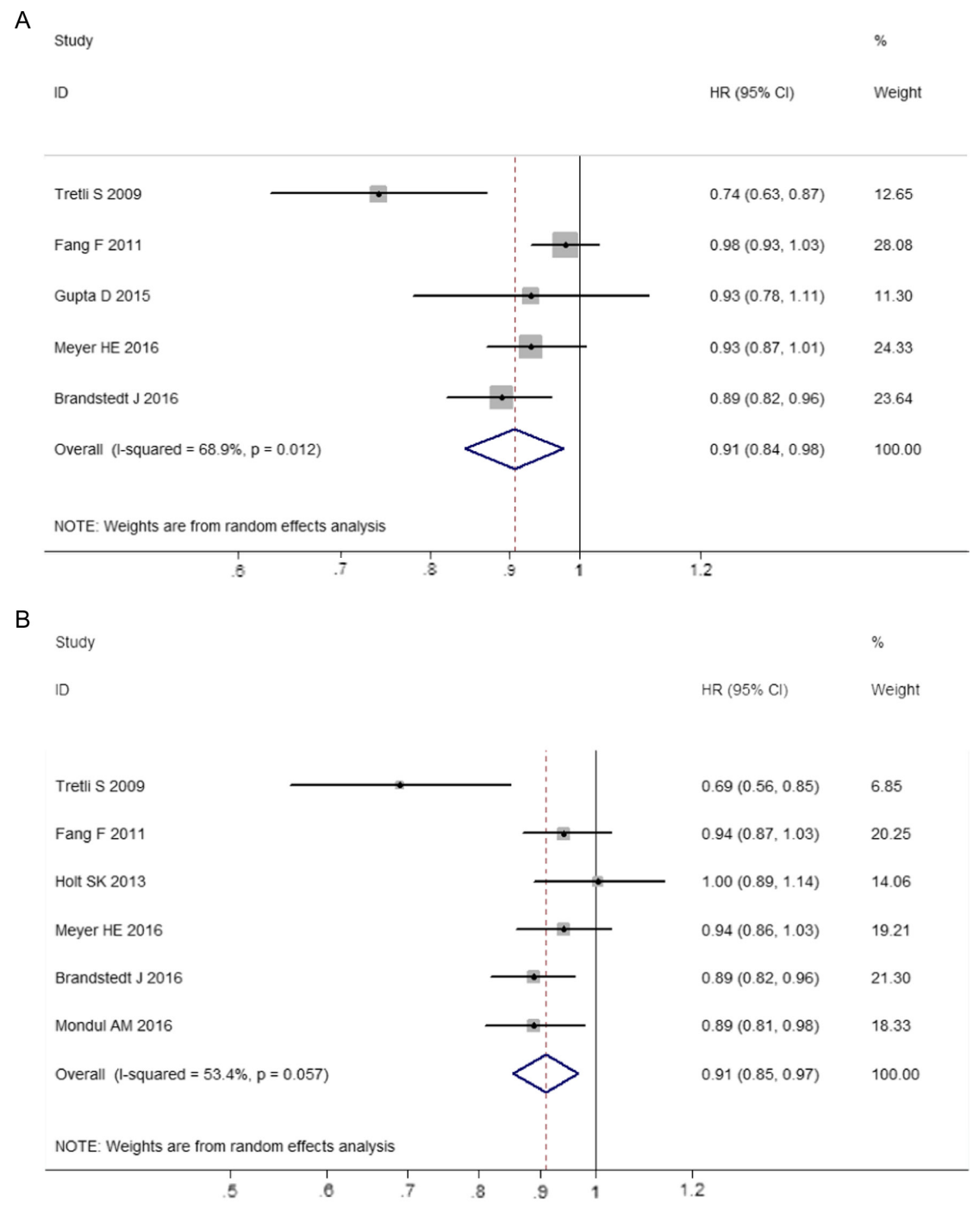

Figure 3

Summary risk estimates of mortality in prostate cancer patients associated with $20 \mathrm{nmol} / \mathrm{L}$ increment in 25(OH)D level. (A) Funnel plot of risk estimates of all-cause mortality of prostate cancer with the increment of $20 \mathrm{nmol} / \mathrm{L}$ in $25(\mathrm{OH}) \mathrm{D}$ level. (B) Funnel plot of risk estimates of prostate cancer-specific mortality with the increment of $20 \mathrm{nmol} / \mathrm{L}$ in $25(\mathrm{OH}) \mathrm{D}$ level. https://ec.bioscientifica.com https://doi.org/10.1530/EC-18-0283 (c) 2018 The authors Published by Bioscientifica Ltd
This work is licensed under a Creative Commons Attribution-NonCommercial 4.0 International License. 
A

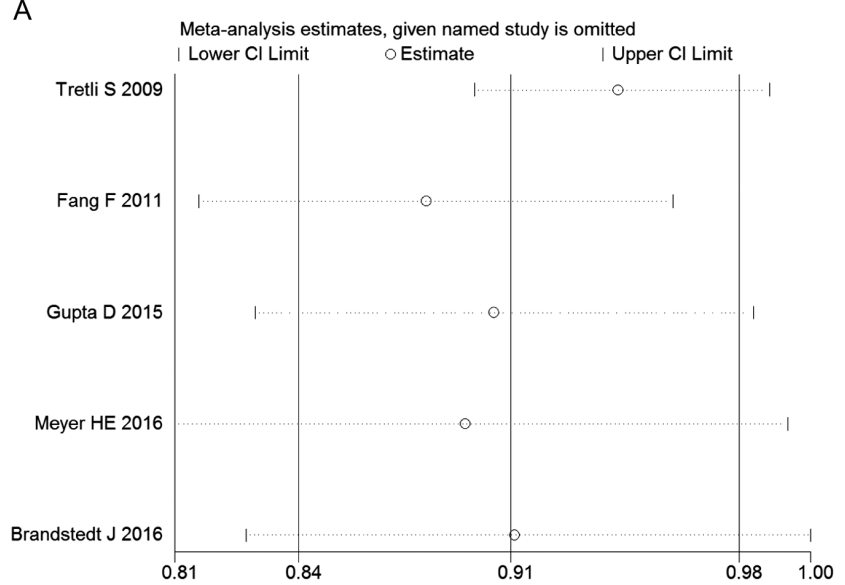

B

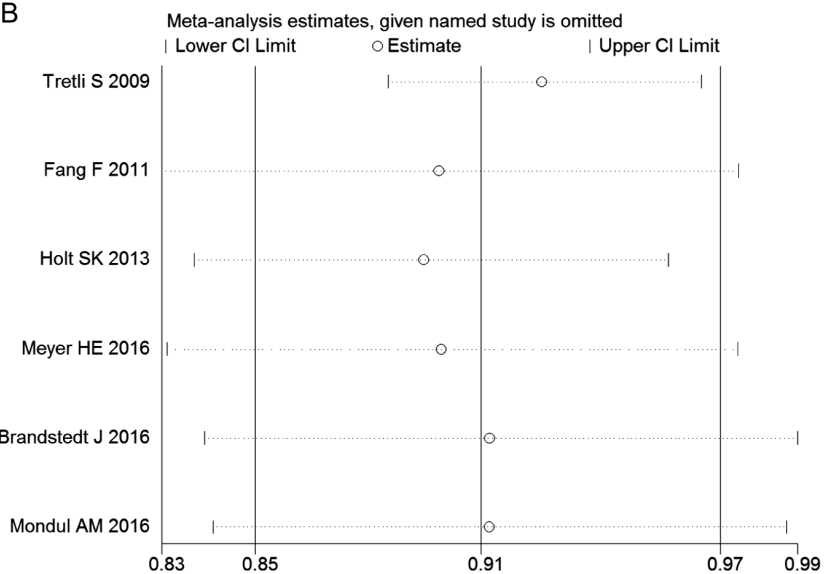

Figure 4

Sensitivity analysis by excluding studies by turns suggested that the pooled HRs were not significantly changed by any individual study. (A) Sensitivity analysis of the association between 25(OH)D and all-cause mortality of prostate cancer. (B) Sensitivity analysis of the association between $25(\mathrm{OH}) \mathrm{D}$ and prostate cancer-specific mortality.

the HR of prostate cancer-specific mortality was 0.91 (95\% CI: 0.88-0.95) for prediagnosis studies and 0.84 (95\% CI: 0.58-1.21) for postdiagnosis ones. The HR of all-cause mortality was 0.94 (95\% CI: 0.88-0.98) in prediagnosis subgroup. Restricting the analysis among more than 10-year follow-up yielded a HR of 0.92 (95\% CI: 0.89-0.96) and 0.94 (95\% CI: 0.89-0.98) for prostate cancer-specific mortality and all-cause mortality respectively, which was slightly higher than the overall results. Moreover, there was no evidence of significant heterogeneity between subgroups with the use of meta-regression analyses.

\section{Discussion}

The role of circulating 25-hydroxyvitamin D and survival outcomes among prostate cancer patients remains unclear

\begin{tabular}{lr}
\hline https://ec.bioscientifica.com & ○ 2018 The authors \\
https://doi.org/10.1530/EC-18-0283 & Published by Bioscientifica Ltd
\end{tabular}

and controversial. This meta-analysis is the first one to focus on the relationship between 25-hydroxyvitamin D and mortality in prostate cancer, involving 7808 participants with survival outcomes. The results calculated from seven eligible studies indicated higher vitamin D level was significantly associated with decreased all-cause mortality and prostate cancer-specific mortality. Further doseresponse analysis showed that every $20 \mathrm{nmol} / \mathrm{L}$ increment in 25-hydroxyvitamin D level was associated with a $9 \%$ lower risk of all-cause mortality and prostate cancerspecific mortality. By conducting the subgroup analysis, we found the results were consistent in prediagnosis and more than 10-year follow-up subgroups. The assessment of vitamin D before diagnosis was more likely to get rid of the influence of prostate cancer on the level of vitamin D and long follow-up time enabled researchers to calculate the outcome events more precisely. Based on the above findings, we conclude that higher circulating vitamin D
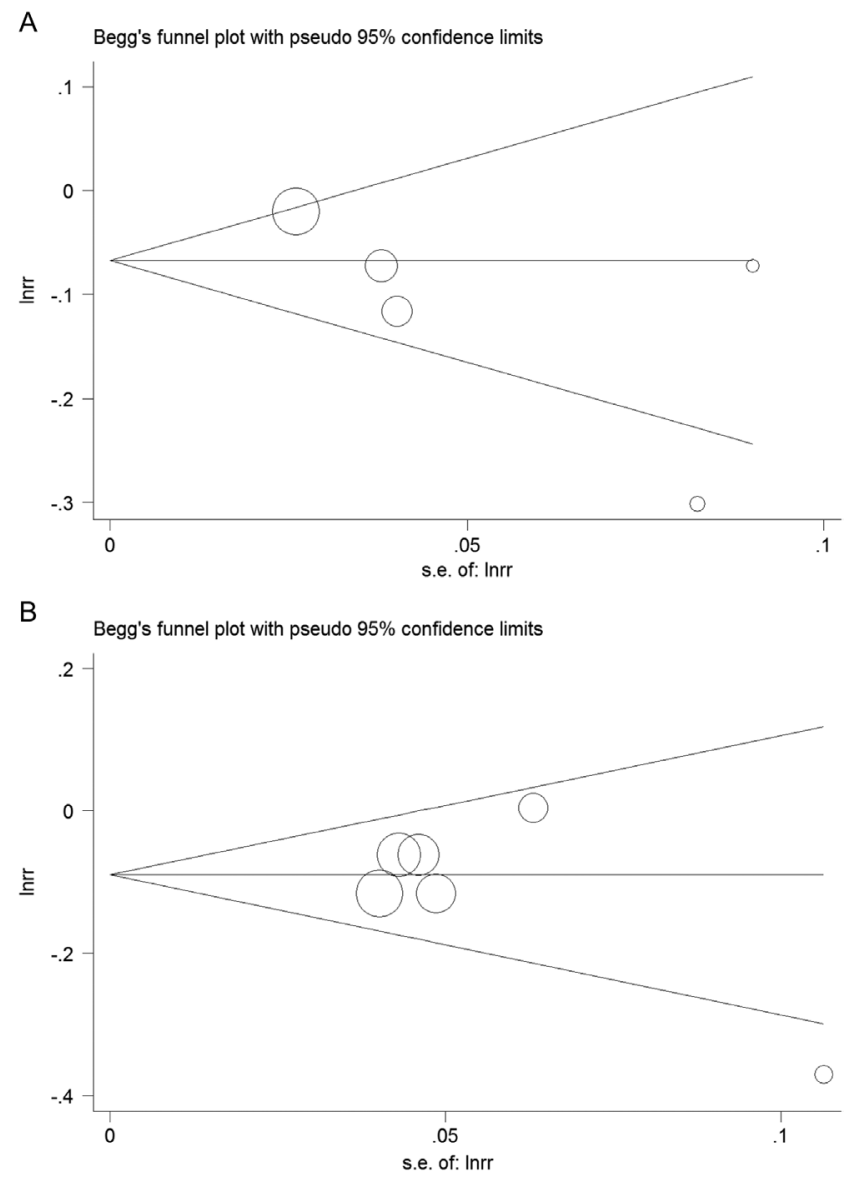

Figure 5

Publication bias. (A) Publication bias of the association between 25(OH)D and all-cause mortality of prostate cancer. (B) Publication bias of the association between 25(OH)D and prostate cancer-specific mortality. 
Table 2 Summary risk estimates of the associations between vitamin D level and prostate cancer mortality.

\begin{tabular}{|c|c|c|c|c|c|c|}
\hline Study characteristics & No. of studies & HR & $95 \% \mathrm{Cl}$ & $\boldsymbol{I}^{2}(\%)$ & $P$ value 1 & $P$ value 2 \\
\hline Studies of PCM & 6 & 0.91 & $0.87-0.97$ & 53.4 & 0.057 & \\
\hline Country & & & & & & 0.294 \\
\hline Europe & 4 & 0.88 & $0.81-0.95$ & 57.9 & 0.068 & \\
\hline USA & 2 & 0.96 & $0.90-1.03$ & 0 & 0.389 & \\
\hline Time of vitamin D assessment & & & & & & 0.36 \\
\hline Postdiagnosis & 2 & 0.84 & $0.58-1.21$ & 89.1 & 0.002 & \\
\hline Prediagnosis & 4 & 0.91 & $0.88-0.95$ & 0 & 0.675 & \\
\hline Follow-up & & & & & & 0.055 \\
\hline Less than 10 years & 1 & & & & & \\
\hline More than 10 years & 5 & 0.92 & $0.89-0.96$ & 0 & 0.479 & \\
\hline Studies of ACM & 5 & 0.91 & $0.84-0.98$ & 68.9 & 0.012 & \\
\hline Country & & & & & & 0.295 \\
\hline Europe & 3 & 0.87 & 0.79 & 68.5 & 0.042 & \\
\hline USA & 2 & 0.98 & $0.93-1.03$ & 0 & 0.576 & \\
\hline Time of vitamin D assessment & & & & & & 0.246 \\
\hline Postdiagnosis & 2 & 0.83 & $0.66-1.04$ & 71.5 & 0.061 & \\
\hline Prediagnosis & 3 & 0.94 & $0.89-0.98$ & 53.9 & 0.114 & \\
\hline Follow-up & & & & & & 0.246 \\
\hline Less than 10 years & 2 & 0.83 & $0.66-1.04$ & 71.5 & 0.061 & \\
\hline More than 10 years & 3 & 0.94 & $0.89-0.98$ & 53.9 & 0.114 & \\
\hline
\end{tabular}

$P$ value 1 for heterogeneity within each subgroup. $P$ value 2 for heterogeneity between subgroups with meta-regression analysis. ACM, all-cause mortality; $\mathrm{Cl}$, confidence interval; HR, summary hazard ratio; PCSM, prostate cancer-specific mortality.

level is associated with a lower risk of death from prostate cancer.

Numerous experimental studies have been done to elucidate the mechanism by which vitamin $\mathrm{D}$ affect the prostate cancer survival. According to previous studies, $1,25(\mathrm{OH})_{2} \mathrm{D}$ could cause cell cycle arrest and induce apoptosis, inhibiting cell proliferation in several prostate cancer cell lines $(38,39,40) .1,25(\mathrm{OH})_{2}$ D played a protective role in preventing normal human prostate epithelial cell lines from oxidative stress in since it increased both the expression and activity of antioxidants, such as glucose6-phosphate dehydrogenase and glutathione (41). BenShoshan and colleagues demonstrated that $1,25(\mathrm{OH})_{2} \mathrm{D}$ inhibited angiogenesis by reducing HIF-1 $\alpha$ expression in various human prostate cancer cell lines (42). In terms of animal model evidence, Ray and colleagues indicated that a diet deficient in vitamin $\mathrm{D}$ rather than vitamin D-sufficient diet accelerated growth of human prostate cancers insensitive to androgen therapy in athymic mice (43). Another study reported that a higher vitamin D3-supplemented diet led to significant tumor shrinkage in mice bearing PC-3 prostate cancer xenografts (44). Moreover, vitamin D could prevent the metastasis of prostate cancer according to several animal and cell experiments $(45,46)$. Therefore, there is some evidence supporting the protective effect of vitamin $\mathrm{D}$ in prostate cancer. However, the underlying molecular mechanisms are still not fully clarified, and more studies are needed to explore them.

Some studies reported that 25-hydroxyvitamin D concentration was correlated with prostate cancer pathology. Researchers found lower 25-hydroxyvitamin D concentrations were positively correlated with higher Gleason grade and tumor stage $(47,48)$. The findings above provide some explanations for the prognostic role of 25-hydroxyvitamin D in prostate cancer.

Previous studies reported conflicting results about the vitamin D and prostate cancer incidence. One metaanalysis showed positive association between high level of vitamin D and increased incidence of prostate cancer (49). Some studies also suggested that high incidence of aggressive prostate cancer in African Americans might be partly due to deficient concentrations of serum vitamin D $(50,51)$. In the contrast, one Mendelian randomization study showed null relationship between vitamin $\mathrm{D}$ and risk of prostate cancer (52). Other studies also failed to find a positive relationship between vitamin $\mathrm{D}$ and prostate cancer risk $(47,53)$. The conflicting findings in the relationship between vitamin $\mathrm{D}$ and prostate cancer risk may result from the some factors, such as different populations, various study design and different confounding factors. The findings in our study suggest that vitamin $\mathrm{D}$ is more likely to be a suppressive and protective factor during the development of prostate
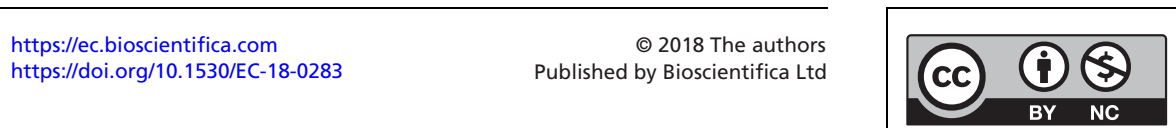
cancer. Therefore, there is still controversy on the role of vitamin $\mathrm{D}$ in prostate cancer, which need to be elucidated in future researches.

There is also some evidence from clinical trials on the roles of vitamin D in prostate cancer. In a clinical trial, low-grade prostate cancer patients took $4000 \mathrm{IU}$ of vitamin D3 every day for a whole year and had a biopsy after the supplementation (54). Results of biopsy revealed a decreased number of positive cores and no increase in Gleason score (54). Several randomized clinical trials showed that oral vitamin D3 modestly decreased the level of PSA (55) and reduced the PSA rise rate $(56,57)$. However, a vitamin D supplementation trial showed no influence on free or total PSA level in African American population (58). At present, the evidence from clinical trials on the roles of vitamin D in prostate cancer is still limited, and more clinical trials are needed.

There are potential limitations existing in our study which should be considered. For one thing, although all studies adjusted for confounding factors, some potential confounding factors related to vitamin D remained residual. For another, some studies included in our meta-analysis tested the circulating vitamin D level postdiagnosis or post treatment, thus it is difficult to get rid of the possibility of reverse causality. What is more, the limited number of included studies restricted us to find the source of heterogeneity.

Based on the results mentioned earlier, we can draw the conclusion that higher vitamin D level is significantly associated with a risk reduction of all-cause mortality and prostate cancer-specific mortality, indicating vitamin D may exert a protective effect in the progression and prognosis of prostate cancer. More cohort studies and randomized clinical trial are needed to further illustrate the role of vitamin D in the pathogenesis and prognosis of prostate cancer.

\section{Declaration of interest}

The authors declare that there is no conflict of interest that could be perceived as prejudicing the impartiality of this review.

\section{Funding}

This work did not receive any specific grant from any funding agency in the public, commercial or not-for-profit sector.

\section{Author contribution statement}

Zhen-yu Song designed the study. Qiuming Yao, Zhi-yuan Zhuo and Zhe Ma extracted the data. Zhen-yu Song and Qiuming Yao performed the analyses. Zhen-yu Song wrote the draft. Gang Chen revised it critically.

\section{References}

1 Siegel RL, Miller KD \& Jemal A. Cancer statistics, 2017. CA: A Cancer Journal for Clinicians 201767 7-30. (https://doi.org/10.3322/ caac.21387)

2 Wilson KM, Giovannucci EL \& Mucci LA. Lifestyle and dietary factors in the prevention of lethal prostate cancer. Asian Journal of Andrology 201214 365-374. (https://doi.org/10.1038/aja.2011.142)

3 Crawford ED, Black L, Eaddy M \& Kruep EJ. A retrospective analysis illustrating the substantial clinical and economic burden of prostate cancer. Prostate Cancer and Prostatic Diseases 201013 162-167. (https://doi.org/10.1038/pcan.2009.63)

4 Scaglione-Sewell BA, Bissonnette M, Skarosi S, Abraham C \& Brasitus TA. A vitamin D3 analog induces a G1-phase arrest in CaCo- 2 cells by inhibiting cdk2 and cdk6: roles of cyclin E, p21Waf1, and p27Kip1. Endocrinology 2000141 3931-3939. (https://doi. org/10.1210/endo.141.11.7782)

5 Diaz GD, Paraskeva C, Thomas MG, Binderup L \& Hague A. Apoptosis is induced by the active metabolite of vitamin D3 and its analogue EB1089 in colorectal adenoma and carcinoma cells: possible implications for prevention and therapy. Cancer Research $2000602304-2312$.

6 Fernandez-Garcia NI, Palmer HG, Garcia M, Gonzalez-Martin A, Del RM, Barettino D, Volpert O, Munoz A \& Jimenez B. 1alpha,25Dihydroxyvitamin D3 regulates the expression of Id1 and Id2 genes and the angiogenic phenotype of human colon carcinoma cells. Oncogene 200524 6533-6544. (https://doi.org/10.1038/ sj.onc.1208801)

7 Evans SR, Shchepotin EI, Young H, Rochon J, Uskokovic M \& Shchepotin IB. 1,25-dihydroxyvitamin D3 synthetic analogs inhibit spontaneous metastases in a 1,2-dimethylhydrazine-induced colon carcinogenesis model. International Journal of Oncology 200016 1249-1254. (https://doi.org/10.3892/ijo.16.6.1249)

8 Chen L, Davey SG, Evans DM, Cox A, Lawlor DA, Donovan J, Yuan W, Day IN, Martin RM, Lane A, et al. Genetic variants in the vitamin d receptor are associated with advanced prostate cancer at diagnosis: findings from the prostate testing for cancer and treatment study and a systematic review. Cancer Epidemiology, Biomarkers and Prevention 200918 2874-2881. (https://doi.org/10.1158/1055-9965. EPI-09-0544)

9 Holt SK, Kwon EM, Koopmeiners JS, Lin DW, Feng Z, Ostrander EA, Peters U \& Stanford JL. Vitamin D pathway gene variants and prostate cancer prognosis. Prostate 201070 1448-1460. (https://doi. org/10.1002/pros.21180)

10 Gupta D, Trukova K, Popiel B, Lammersfeld C \& Vashi PG. The association between pre-treatment serum 25-hydroxyvitamin D and survival in newly diagnosed stage IV prostate cancer. PLos ONE 2015 10 e119690. (https://doi.org/10.1371/journal.pone.0119690)

11 Fang F, Kasperzyk JL, Shui I, Hendrickson W, Hollis BW, Fall K, Ma J, Gaziano JM, Stampfer MJ, Mucci LA \& Giovannucci E. Prediagnostic plasma vitamin D metabolites and mortality among patients with prostate cancer. PLoS ONE 20116 e18625. (https://doi.org/10.1371/ journal.pone.0018625)

12 Brandstedt J, Almquist M, Manjer J \& Malm J. Vitamin D, PTH, and calcium in relation to survival following prostate cancer. Cancer Causes and Control 201627 669-677. (https://doi.org/10.1007/ s10552-016-0740-7)

13 Margulis AV, Pladevall M, Riera-Guardia N, Varas-Lorenzo C, Hazell L, Berkman ND, Viswanathan M \& Perez-Gutthann S. Quality assessment of observational studies in a drug-safety systematic review, comparison of two tools: the Newcastle-Ottawa Scale and the RTI item bank. Clinical Epidemiology 20146 359-368. (https://doi. org/10.2147/CLEP.S66677)

14 Greenland S \& Longnecker MP. Methods for trend estimation from summarized dose-response data, with applications to meta-analysis.

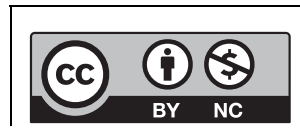


American Journal of Epidemiology 1992135 1301-1309. (https://doi. org/10.1093/oxfordjournals.aje.a116237)

15 Orsini N, Bellocco R \& Greenland S. Generalized least squares for trend estimation of summarized dose-response data. Stata Journal $2006640-57$.

16 Higgins JP, Thompson SG, Deeks JJ \& Altman DG. Measuring inconsistency in meta-analyses. BMJ 2003327 557-560. (https://doi. org/10.1136/bmj.327.7414.557)

17 Cochran WG. The combination of estimates from different experiments. Biometrics 195410 101-129. (https://doi. $\operatorname{org} / 10.2307 / 3001666)$

18 DerSimonian R \& Laird N. Meta-analysis in clinical trials. Controlled Clinical Trials 19867 177-188. (https://doi.org/10.1016/01972456(86)90046-2)

19 Egger M, Davey SG, Schneider M \& Minder C. Bias in meta-analysis detected by a simple, graphical test. BMJ 1997315 629-634. (https:// doi.org/10.1136/bmj.315.7109.629)

20 Feldman D, Krishnan AV, Swami S, Giovannucci E \& Feldman BJ. The role of vitamin D in reducing cancer risk and progression. Nature Reviews Cancer 201414 342-357. (https://doi.org/10.1038/nrc3691)

21 Giovannucci E, Liu Y, Rimm EB, Hollis BW, Fuchs CS, Stampfer MJ \& Willett WC. Prospective study of predictors of vitamin D status and cancer incidence and mortality in men. Journal of the National Cancer Institute 200698 451-459. (https://doi.org/10.1093/jnci/djj101)

22 Shui IM, Mucci LA, Kraft P, Tamimi RM, Lindstrom S, Penney KL, Nimptsch K, Hollis BW, Dupre N, Platz EA, et al. Vitamin D-related genetic variation, plasma vitamin $\mathrm{D}$, and risk of lethal prostate cancer: a prospective nested case-control study. Journal of the National Cancer Institute 2012104 690-699. (https://doi.org/10.1093/jnci/djs189)

23 Tretli S, Hernes E, Berg JP, Hestvik UE \& Robsahm TE. Association between serum $25(\mathrm{OH}) \mathrm{D}$ and death from prostate cancer. British Journal of Cancer 2009100 450-454. (https://doi.org/10.1038/ sj.bjc.6604865)

24 Shui IM, Mondul AM, Lindstrom S, Tsilidis KK, Travis RC, Gerke T, Albanes D, Mucci LA, Giovannucci E \& Kraft P. Circulating vitamin $\mathrm{D}$, vitamin D-related genetic variation, and risk of fatal prostate cancer in the National Cancer Institute Breast and Prostate Cancer Cohort Consortium. Cancer 2015121 1949-1956. (https://doi. org/10.1002/cncr.29320)

25 Buttigliero C, Monagheddu C, Petroni P, Saini A, Dogliotti L, Ciccone $\mathrm{G} \&$ Berruti A. Prognostic role of vitamin d status and efficacy of vitamin D supplementation in cancer patients: a systematic review. Oncologist 201116 1215-1227. (https://doi. org/10.1634/theoncologist.2011-0098)

26 Dimitrakopoulou VI, Travis RC, Shui IM, Mondul A, Albanes D, Virtamo J, Agudo A, Boeing H, Bueno-de-Mesquita HB, Gunter MJ, et al. Interactions between genome-wide significant genetic variants and circulating concentrations of 25-hydroxyvitamin D in relation to prostate cancer risk in the National Cancer Institute BPC3. American Journal of Epidemiology 2017185 452-464. (https://doi.org/10.1093/ aje/kww143)

27 Porojnicu A, Robsahm TE, Berg JP \& Moan J. Season of diagnosis is a predictor of cancer survival. Sun-induced vitamin D may be involved: a possible role of sun-induced Vitamin D. Journal of Steroid Biochemistry and Molecular Biology 2007103 675-678. (https://doi. org/10.1016/j.jsbmb.2006.12.031)

28 Mondul AM, Weinstein SJ, Moy KA, Mannisto S \& Albanes D. Circulating 25-hydroxyvitamin D and prostate cancer survival. Cancer Epidemiology, Biomarkers and Prevention 201625 665-669. (https://doi.org/10.1158/1055-9965.EPI-15-0991)

29 Paller CJ, Kanaan YM, Beyene DA, Naab TJ, Copeland RL, Tsai HL, Kanarek NF \& Hudson TS. Risk of prostate cancer in AfricanAmerican men: evidence of mixed effects of dietary quercetin by serum vitamin D status. Prostate 201575 1376-1383. (https://doi. org/10.1002/pros.23018)
30 Fang F, Kasperzyk JL, Shui I, Hendrickson W, Hollis BW, Fall K, Ma J Gaziano JM, Stampfer MJ, Mucci LA, et al. Prediagnostic plasma vitamin D metabolites and mortality among patients with prostate cancer. PLOS ONE 20116 e18625. (https://doi.org/10.1371/journal. pone.0018625)

31 Meyer HE, Stoer NC, Samuelsen SO, Blomhoff R, Robsahm TE, Brustad M, Giovannucci EL \& Bjorge T. Long term association between serum 25-hydroxyvitamin $\mathrm{D}$ and mortality in a cohort of 4379 men. PLoS ONE 201611 e151441. (https://doi.org/10.1371/ journal.pone.0151441)

32 Robsahm TE, Tretli S, Dahlback A \& Moan J. Vitamin D3 from sunlight may improve the prognosis of breast-, colon- and prostate cancer (Norway). Cancer Causes and Control 200415 149-158. (https://doi.org/10.1023/B:CACO.0000019494.34403.09)

33 Brandstedt J, Almquist M, Manjer J \& Malm J. Vitamin D, PTH, and calcium in relation to survival following prostate cancer. Cancer Causes and Control 201627 669-677. (https://doi.org/10.1007/ s10552-016-0740-7)

34 Holt SK, Kolb S, Fu R, Horst R, Feng Z \& Stanford JL. Circulating levels of 25-hydroxyvitamin $\mathrm{D}$ and prostate cancer prognosis. Cancer Epidemiology 201337 666-670. (https://doi.org/10.1016/j. canep.2013.07.005)

35 Grant WB. The likely role of vitamin D from solar ultraviolet-B irradiance in increasing cancer survival. Anticancer Research 200626 2605-2614

36 Der T, Bailey BA, Youssef D, Manning T, Grant WB \& Peiris AN. Vitamin D and prostate cancer survival in veterans. Military Medicine 2014179 81-84. (https://doi.org/10.7205/MILMED-D-12-00540)

37 Atoum MF, AlKateeb D \& AlHaj MS. The Fok1 vitamin D receptor gene polymorphism and 25(OH) D serum levels and prostate cancer among Jordanian men. Asian Pacific Journal of Cancer Prevention 2015 16 2227-2230. (https://doi.org/10.7314/APJCP.2015.16.6.2227)

38 Blut SE, Mcdonnel TJ, Polek TC \& Weigel NL. Calcitriol-induced apoptosis in LNCaP cells is blocked by overexpression of Bcl2. Endocrinology 2000141 10-17. (https://doi.org/10.1210/ endo.141.1.7289)

39 Ikeda N, Uemura H, Ishiguro H, Hori M, Hosaka M, Kyo S, Miyamoto K, Takeda E \& Kubota Y. Combination treatment with 1alpha,25-dihydroxyvitamin D3 and 9-cis-retinoic acid directly inhibits human telomerase reverse transcriptase transcription in prostate cancer cells. Molecular Cancer Therapeutics 20032 739-746.

40 Rohan JN \& Weigel NL. 1Alpha,25-dihydroxyvitamin D3 reduces c-Myc expression, inhibiting proliferation and causing G1 accumulation in C4-2 prostate cancer cells. Endocrinology 2009150 2046-2054. (https://doi.org/10.1210/en.2008-1395)

41 Bao BY, Ting HJ, Hsu JW \& Le YF. Protective role of 1 alpha, 25-dihydroxyvitamin D3 against oxidative stress in nonmalignant human prostate epithelial cells. International Journal of Cancer 2008 122 2699-2706. (https://doi.org/10.1002/ijc.23460)

42 Ben-Shoshan M, Amir S, Dang DT, Dang LH, Weisman Y \& Mabjeesh NJ. 1alpha,25-dihydroxyvitamin D3 (Calcitriol) inhibits hypoxia-inducible factor-1/vascular endothelial growth factor pathway in human cancer cells. Molecular Cancer Therapeutics 20076 1433-1439. (https://doi.org/10.1158/1535-7163.MCT-06-0677)

43 Ray R, Banks M, Abuzahra H, Eddy VJ, Persons KS, Lucia MS, Lambert JR \& Holick MF. Effect of dietary vitamin D and calcium on the growth of androgen-insensitive human prostate tumor in a murine model. Anticancer Research 201232 727-731.

44 Swami S, Krishnan AV, Wang JY, Jensen K, Horst R, Albertelli MA \& Feldman D. Dietary vitamin $\mathrm{D}(3)$ and 1,25-dihydroxyvitamin $\mathrm{D}(3)$ (calcitriol) exhibit equivalent anticancer activity in mouse xenograft models of breast and prostate cancer. Endocrinology 2012153 2576-2587. (https://doi.org/10.1210/en.2011-1600)

45 Krishnan AV, Shinghal R, Raghavachari N, Brooks JD \& Peehl DM. Analysis of vitamin D-regulated gene expression in LNCaP human https://ec.bioscientifica.com https://doi.org/10.1530/EC-18-0283 (c) 2018 The authors Published by Bioscientifica Ltd

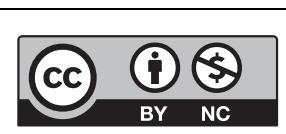

This work is licensed under a Creative Commons Attribution-NonCommercial 4.0 International License. 
prostate cancer cells using cDNA microarrays. Prostate 200459 243-251. (https://doi.org/10.1002/pros.20006)

46 Tokar EJ \& Webber MM. Cholecalciferol (vitamin D3) inhibits growth and invasion by up-regulating nuclear receptors and 25-hydroxylase (CYP27A1) in human prostate cancer cells. Clinical and Experimental Metastasis 200522 275-284. (https://doi.org/10.1007/s10585-0058393-z)

47 Gilbert R, Metcalfe C, Fraser WD, Donovan J, Hamdy F, Neal DE, Lane JA \& Martin RM. Associations of circulating 25-hydroxyvitamin $\mathrm{D}$ with prostate cancer diagnosis, stage and grade. International Journal of Cancer 2012131 1187-1196. (https://doi.org/10.1002/ ijc.27327)

48 Nyame YA, Murphy AB, Bowen DK, Jordan G, Batai K, Dixon M, Hollowel CM, Kielb S, Meeks JJ, Gan PH, et al. Associations between serum vitamin $\mathrm{D}$ and adverse pathology in men undergoing radical prostatectomy. Journal of Clinical Oncology 201634 1345-1349. (https://doi.org/10.1200/JCO.2015.65.1463)

49 Xu Y, Shao X, Yao Y, Xu L, Chang L, Jiang Z \& Lin Z. Positive association between circulating 25-hydroxyvitamin D levels and prostate cancer risk: new findings from an updated meta-analysis. Journal of Cancer Research and Clinical Oncology 2014140 1465-1477. (https://doi.org/10.1007/s00432-014-1706-3)

50 Nelson SM, Batai K, Ahaghotu C, Agurs-Collins T \& Kittles RA. Association between serum 25-hydroxy-vitamin D and aggressive prostate cancer in African American men. Nutrients 2016912 (https://doi.org/10.3390/nu9010012)

51 Jackson MD, Tulloch-Reid MK, Lindsay CM, Smith G, Bennet FI, McFarlane-Anderson N, Aiken W \& Coard KC. Both serum 25-hydroxyvitamin D and calcium levels may increase the risk of incident prostate cancer in Caribbean men of African ancestry. Cancer Medicine 20154 925-935. (https://doi.org/10.1002/cam4.457)

52 Dimitrakopoulou VI, Tsilidis KK, Haycock PC, Dimou NL, Al-Dabhani K, Martin RM, Lewis SJ, Gunter MJ, Mondul A, Shui IM, et al. Circulating vitamin D concentration and risk of seven cancers: mendelian randomisation study. BMJ 2017359 j4761. (https://doi. org/10.1136/bmj.j4761)

53 Ordóñez-Mena JM, Schöttker B, Fedirko V, Jenab M, Olsen A, Halkjær J, Kampman E, de Groot L, Jansen E, Bueno-de-Mesquita HB, et al. Pre-diagnostic vitamin D concentrations and cancer risks in older individuals: an analysis of cohorts participating in the CHANCES consortium. European Journal of Epidemiology 201631 311-323. (https://doi.org/10.1007/s10654-015-0040-7)

54 Marshal DT, Savage SJ, Garrett-Mayer E, Keane TE, Hollis BW, Horst RL, Ambrose LH, Kindy MS \& Gattoni-Celli S. Vitamin D3 supplementation at 4000 international units per day for one year results in a decrease of positive cores at repeat biopsy in subjects with low-risk prostate cancer under active surveillance. Journal of Clinical Endocrinology and Metabolism 201297 2315-2324. (https://doi. org/10.1210/jc.2012-1451)

55 Wagner D, Trudel D, Van der Kwast T, Nonn L, Giangreco AA, Li D, Dias A, Cardoza M, Laszlo S, Hersey K, Klotz L, Finelli A, Fleshner N \& Vieth R. Randomized clinical trial of vitamin D3 doses on prostatic vitamin D metabolite levels and ki67 labeling in prostate cancer patients. Journal of Clinical Endocrinology and Metabolism 201398 1498-1507. (https://doi.org/10.1210/jc.2012-4019)

56 Gross C, Stamey T, Hancock S \& Feldman D. Treatment of early recurrent prostate cancer with 1,25-dihydroxyvitamin D3 (calcitriol). Journal of Urology 1998159 2035-2039 2039-2040. (https://doi. org/10.1016/S0022-5347(01)63236-1)

57 Beer TM, Lemmon D, Lowe BA \& Henner WD. High-dose weekly oral calcitriol in patients with a rising PSA after prostatectomy or radiation for prostate carcinoma. Cancer 200397 1217-1224. (https://doi.org/10.1002/cncr.11179)

58 Chandler PD, Giovannucci EL, Scot JB, Bennet GG, Ng K, Chan AT, Hollis BW, Emmons KM, Fuchs CS \& Drake BF. Null association between vitamin D and PSA levels among black men in a vitamin D supplementation trial. Cancer Epidemiology, Biomarkers and Prevention 201423 1944-1947. (https://doi.org/10.1158/1055-9965.EPI-14-0522)

Received in final form 3 September 2018

Accepted 8 October 2018

Accepted Preprint published online 9 October 2018

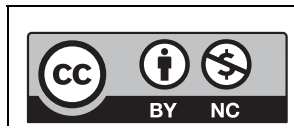

This work is licensed under a Creative Commons Attribution-NonCommercial 4.0 International License. 